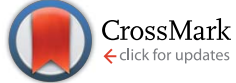

Cite this: J. Mater. Chem. A, 2014, 2, 20676

Received 11th September 2014 Accepted 29th October 2014

DOI: $10.1039 / c 4 t a 04749 d$

www.rsc.org/MaterialsA

\section{Enhanced thermo-electrochemical power using carbon nanotube additives in ionic liquid redox electrolytes $\uparrow$}

\author{
Pablo F. Salazar, ${ }^{a}$ Sai T. Stephens, ${ }^{a}$ Ali H. Kazim, ${ }^{a}$ Jennifer M. Pringle ${ }^{b}$ \\ and Baratunde A. Cola*ac
}

Waste heat recovery with thermo-electrochemical cells is limited by their low power and conversion efficiencies. Here we explore ionic liquid electrolytes mixed with multiwall carbon nanotubes (MWCNTs) as alternative electrolytes for thermo-electrochemical cells. The results show that, upon addition of MWCNTs, the combination of interfacial polarization and ion pair dissociation reduces mass transfer resistances and enhances the power of thermo-electrochemical cells at low weight percentage of MWCNTs by up to $30 \%$. This occurs in spite of reduced open circuit voltage due to percolated networks.

\section{Introduction}

Thermo-electrochemical cells, ${ }^{\mathbf{1 , 2}}$ also known as thermocells, are electrochemical devices that produce a steady electric current under an applied temperature difference between two electrodes (Fig. S1 $\dagger$ ). Thermocells are promising alternative devices to harvest waste heat from close-to-room temperature sources (less than 230 degrees celsius). In contrast to solid-state thermoelectrics, thermocells, can have substantially greater thermal-to-voltage conversion (more than 1.4 millivolts per degree Kelvin $)^{3-5}$ and potentially lower cost. ${ }^{5}$ The energy conversion efficiency of thermocells, however, is limited by the slower transport of ions, instead of electrons as in semiconductor thermoelectrics. Following our recent demonstration of enhanced electrical conductivity in mixtures of multiwall carbon nanotubes (MWCNTs) and imidazolium-based ionic liquids (IL), ${ }^{6}$ here we show that the addition of MWCNTs to redox ILs also enhances the electrical conductivity, and, at low concentration of MWCNTs (less than 0.5 weight percentage), increases the electric power generation of thermocells by as much as 1.3 times the original power. This increase in power results from reduced mass transfer resistances through interfacial polarization and ion pair dissociation, and by optimizing the concentration of MWCNTs to minimize electronic leakage. Phonon scattering at interfaces ${ }^{7}$ limits the increase in thermal

${ }^{a}$ George W. Woodruff School of Mechanical Engineering, Georgia Institute of Technology, Atlanta, Georgia 30332, USA

${ }^{b} A R C$ Centre of Excellence for Electromaterials Science, Institute for Frontier Materials, Deakin University, Burwood, Victoria, Australia

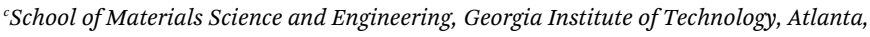
Georgia 30332, USA. E-mail: cola@gatech.edu

$\dagger$ Electronic supplementary information (ESI) available: Experimental details and additional experimental results. See DOI: 10.1039/c4ta04749d conductivity from the addition of MWCNTs to less than half the increase in thermocell power, resulting in higher conversion efficiencies.

Thermocells consist of a redox electrolyte that generates an open circuit voltage, $V_{\text {oc }}$, following: ${ }^{2}$

$$
V_{\mathrm{oc}}=-\frac{\Delta S_{\mathrm{rx}}^{\mathrm{o}}\left(T_{\mathrm{h}}-T_{\mathrm{c}}\right)}{n F} .
$$

Where $\Delta S_{\mathrm{rx}}^{\mathrm{o}}$ is the standard redox reaction entropy of the electrolyte, $F$ is the Faraday constant, $n$ is the number of electrons transferred in the redox reaction, and $T_{\mathrm{h}}$ and $T_{\mathrm{c}}$ are the temperature at the hot and cold electrode, respectively. A conventional electrolyte for thermocells is an aqueous solution of potassium ferri- and ferro-cyanide; ${ }^{8,9}$ while recently, a novel cobalt-based redox couple diluted in an IL has been proposed as an alternative electrolyte., ${ }^{3,10}$ Both redox couples show fast kinetics on platinum electrodes, as well as on less expensive MWCNT and poly(3,4-ethylenedioxythiophene electrodes., ${ }^{\mathbf{5 1 1}, 12}$ Therefore, the electric power with these electrolytes is limited primarily by the ionic flux in the solution, given by: ${ }^{2}$

$$
\vec{N}_{\mathrm{i}}=\underbrace{-D_{\mathrm{i}} \nabla c_{\mathrm{i}}}_{\text {diffusion }} \underbrace{-Z_{\mathrm{i}} u_{\mathrm{i}} \mathrm{F} c_{\mathrm{i}} \nabla \phi}_{\text {migration }} \underbrace{-\frac{Q_{\mathrm{i}}}{\mathrm{R} T^{2}} D_{\mathrm{i}} c_{\mathrm{i}} \nabla T}_{\text {thermal diffusion }} \underbrace{+c_{\mathrm{i}} \vec{u}}_{\text {convection }}
$$

where $\vec{N}_{\mathrm{i}}$ is the ionic density flux of ion i, $D_{\mathrm{i}}$ is the ionic diffusion coefficient, $c_{\mathrm{i}}$ is the ion concentration, $z_{\mathrm{i}}$ is the ionic charge, $u_{\mathrm{i}}$ is the ionic mobility, $\phi$ is the electrostatic potential, $Q_{\mathrm{i}}$ is the ion heat of transport, $R$ is the gas constant, $T$ is the temperature and $\vec{u}$ is the bulk velocity.

The main practical advantage of IL electrolytes compared to aqueous electrolytes is that they can be used in thermocells to harvest waste heat at higher temperatures $\left(150-200{ }^{\circ} \mathrm{C}\right) .^{\mathbf{3 , 1 3 , 1 4}}$ However, ILs usually have a viscosity that is 25 times or more greater than that of water, ${ }^{15}$ which decreases the rate of ion 
diffusion and the ohmic conductivity of the electrolyte. Thus, reducing the mass transfer limitations in ILs remains a major barrier to their use in thermocells.

We recently reported ${ }^{6}$ that the addition of MWCNTs to imidazolium-based ILs decreases the ohmic resistance of the solution due to the formation of percolated networks, interfacial polarization, and ion-pair dissociation (Fig. 1a). The MWCNTs are polarized when an electric field is applied, and the ions are attracted to the charged surfaces (interfacial polarization), facilitating dielectric breakdown and increased ohmic conductivity. ${ }^{\mathbf{1 6 , 1 7}}$ In addition, the imidazolium cations are attracted to the MWCNT surface by weak van der Waals forces, leading to ion-pair dissociation and faster diffusion of the anions. ${ }^{6,18}$ Here we show that the combination of these effects can be optimized at low concentrations of MWCNTs to enhance the power of thermocells, despite the reduced open circuit

a

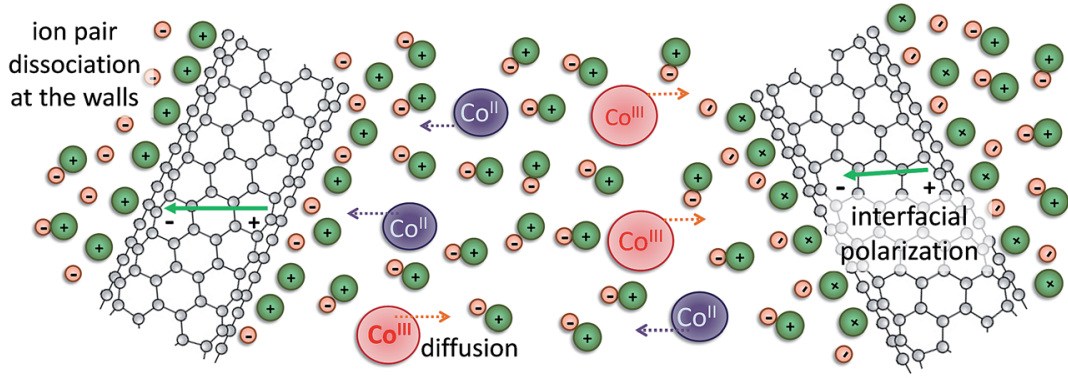

$\odot\left[\mathrm{NTf}_{2}\right]^{-} \oplus[\mathrm{EMIM}]^{+}$

$\odot+[\mathrm{EMIM}]\left[\mathrm{NTf}_{2}\right]$ ion pair

(COII) $\mathrm{Co}^{\prime \prime}(\mathrm{bpy})_{3}\left(\mathrm{NTf}_{2}\right)_{2}$

b

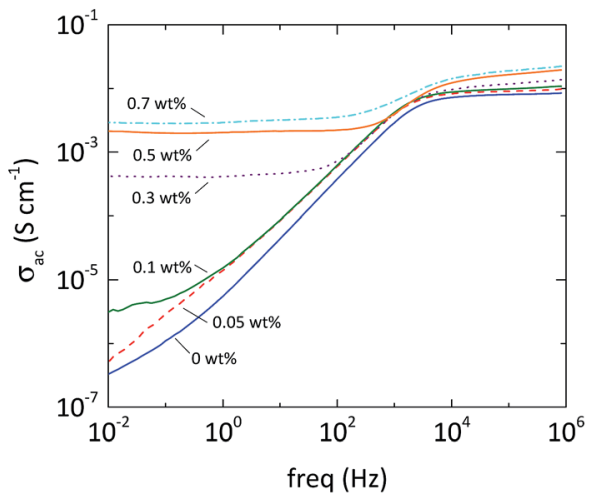

d

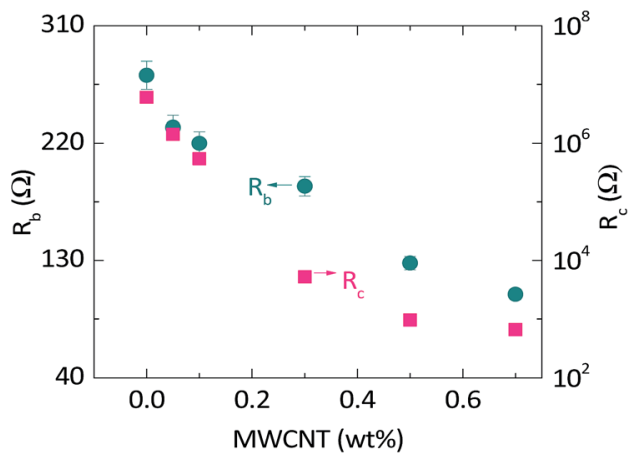

$\mathrm{Co}$ "II'(bpy) $)_{3}\left(\mathrm{NTf}_{2}\right)_{3}$

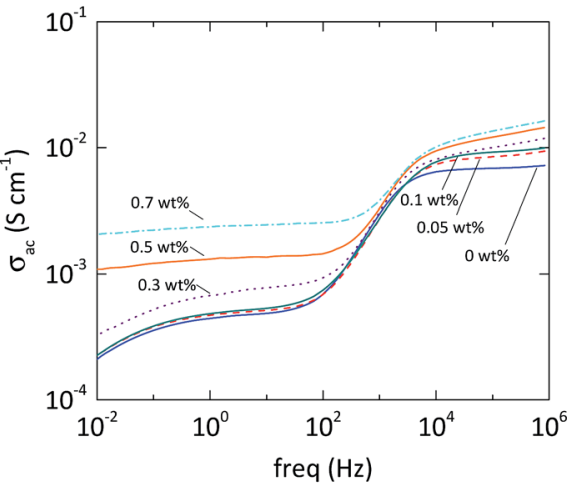

e

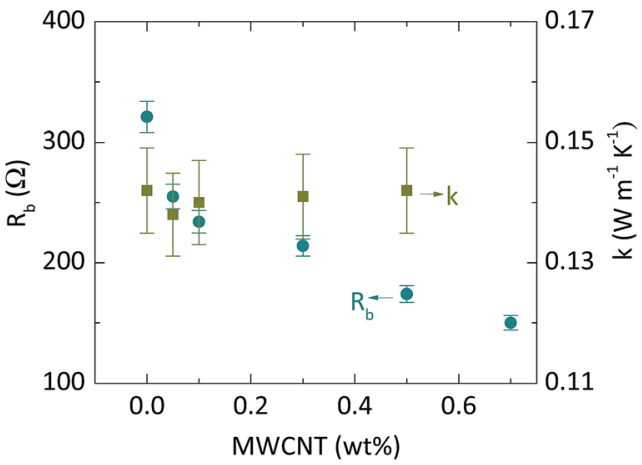

Fig. 1 Molecular conformations, impedance spectroscopy and electrochemical fitting of imidazolium-based IL redox electrolytes mixed with MWCNTs. (a) Illustration of the molecular effects in MWCNT-[EMIM][NTf ${ }_{2}$-CO"/Co"I electrolytes that contribute to enhanced power in thermoelectrochemical cells: ion pair dissociation and interfacial polarization at the MWCNT surface, and ionic diffusion. (b) Frequency dependence of ac conductivity, $\sigma_{\mathrm{ac}}$, for [EMIM][NTf ${ }_{2}$ ] mixed with MWCNT powders at 0 (solid blue), 0.05 (dash red), 0.1 (solid green), 0.3 (dot purple), 0.5 (solid orange) and 0.7 (dot-dash cyan) weight percentage (wt\%). (c) Frequency dependence of ac conductivity, $\sigma_{\mathrm{ac}}$, for $0.025 \mathrm{M} \mathrm{Co}$ (bpy) ${ }_{3}\left(\mathrm{NTf} \mathrm{f}_{2}\right)_{2} /$ $\mathrm{Co}^{\prime \prime \prime}(\mathrm{bpy})_{3}\left(\mathrm{NTf}_{2}\right)_{3}-[\mathrm{EMIM}]\left[\mathrm{NTf}_{2}\right]$ mixed with MWCNT powders at 0 (solid blue), 0.05 (dash red), 0.1 (solid green), 0.3 (dot purple), 0.5 (solid orange) and $0.7 \mathrm{wt} \%$ (dot-dash cyan). (d) Bulk and percolated resistance, $R_{\mathrm{b}}$ and $R_{\mathrm{c}}$, respectively, as MWCNTs are added in [EMIM][NTf $\mathrm{F}_{2}$. (e) Bulk resistance, $R_{\mathrm{b}}$, and thermal conductivity, $k$, as MWCNTs are added in $0.025 \mathrm{M} \mathrm{Co}^{\prime \prime}(\mathrm{bpy})_{3}\left(\mathrm{NTf}_{2}\right)_{2} / \mathrm{Co}^{\prime \prime \prime}(\mathrm{bpy})_{3}(\mathrm{NTf})_{3}-\left[\mathrm{EMIM]}\left[\mathrm{NTf} \mathrm{f}_{2}\right]\right.$. The percolated resistance, $R_{\mathrm{C}}$, was not found in this case because the model was overdetermined. 
voltage that results from the partially percolated MWCNT networks. We measure the electric power of thermocells using a cobalt-based redox couple $0.025 \mathrm{M}$ equimolar tris(bipyridyl) cobalt(II) bis(trifluoromethane sulfonyl)-amide/tris(bipyridyl) cobalt(III) bis(trifluoromethane sulfonyl)-amide $\left(\mathrm{Co}^{\mathrm{II}}\right.$ (bpy) ${ }_{3}$ $\left.\left(\mathrm{NTf}_{2}\right)_{2} / \mathrm{Co}^{\mathrm{III}}(\mathrm{bpy})_{3}\left(\mathrm{NTf}_{2}\right)_{3}\right)$ mixed in an IL (1-ethyl-3-methylimidazolium bis(trisfluoromethanesulfonyl) amide ([EMIM]$\left.\left[\mathrm{NTf}_{2}\right]\right)$ ). We also measure an IL (1-methyl-3-propylimidazolium iodide, [PMIM] $[\mathrm{I}]$ ) that is both the solvent and source of redox ions (see Experimental section for additional details). We measure electrical and thermal conductivity of the electrolytes and show that the increase in electrical conductivity from the addition of MWCNTs can be more than 8 times the increase in thermal conductivity, which makes our approach well suited for improving the efficiency of thermo-electrochemical energy conversion.

\section{Experimental}

\section{Synthesis of Co ${ }^{\mathrm{II}}(\mathrm{bpy})_{3}\left(\mathrm{NTf}_{2}\right)_{2} / \mathrm{Co}^{\mathrm{III}}(\mathrm{bpy})_{3}\left(\mathrm{NTf}_{2}\right)_{3}$}

The cobalt redox couple was synthesized following our previously reported procedures. ${ }^{3}$ The purity was confirmed by ${ }^{1} \mathrm{H}$, ${ }^{19} \mathrm{~F},{ }^{13} \mathrm{C}$ NMR and MS. Reagents were purchased and used as received from Sigma Aldrich and 3M.

\section{Tris(bipyridyl)cobalt(II) bis(trifluoromethanesulfonyl) amide,} $\mathrm{Co}^{\mathrm{II}}(\mathrm{bpy})_{3}\left(\mathrm{NTf}_{2}\right)_{2}$

$\mathrm{Co}^{\mathrm{II}} \mathrm{Cl}_{2} \cdot 6 \mathrm{H}_{2} \mathrm{O}(2.00 \mathrm{~g}, 8.41 \mathrm{mmol})$ and 2,2'-bipyridyl $(4.40 \mathrm{~g}$, $27.88 \mathrm{mmol}$ ) were dissolved in methanol $(25 \mathrm{~mL})$ and the solution refluxed for two hours. An excess of lithium bis(trifluoromethanesulfonyl)amide (3 M) (3.62 g, $12.60 \mathrm{mmol})$ was added and the solution stirred at room temperature for one hour. Upon addition of a small amount of water $(5 \mathrm{~mL})$ the crude product precipitated out of solution. This was removed by filtration, washed with deionized water $(5 \times 50 \mathrm{~mL})$ and dried under high vacuum for 8 hours.

Tris(bipyridyl)cobalt(III) bis(trifluoromethanesulfonyl)amide, $\mathrm{Co}^{\text {III }}(\text { bpy })_{3}\left(\mathrm{NTf}_{2}\right)_{3}$

$\mathrm{Co}^{\mathrm{II}}(\mathrm{bpy})_{3}\left(\mathrm{NTf}_{2}\right)_{2}$ (2 g, $\left.1.84 \mathrm{mmol}\right)$ was dissolved in dry acetonitrile $(15 \mathrm{~mL})$ and nitrosyl tetrafluoroborate $(1.50 \mathrm{mmol}, 0.175$ g) added slowly with stirring. The solution was then stirred at room temperature for one hour. An excess of lithium bis(trifluoromethanesulfonyl)amide (3 M) (0.62 g, $2.16 \mathrm{mmol})$ was added and the solution stirred at room temperature for another hour. The precipitated product was removed by filtration, washed with deionized water $(5 \times 50 \mathrm{~mL})$ and dried under high vacuum for 8 hours.

\section{Materials and sample preparation}

[EMIM] $\left[\mathrm{NTf}_{2}\right]$ and $[\mathrm{PMIM}][\mathrm{I}]$ (purity $>99 \%$ ) were purchased from IOLITEC; and MWCNTs from US-nano. According to product specifications, the MWCNTs had a length of 10-20 $\mu \mathrm{m}$, outside diameter of $50-80 \mathrm{~nm}$, and density of $2.1 \mathrm{~g} \mathrm{~cm}^{-3}$. Fig. S2a and $\mathrm{S} 2 \mathrm{~b} \dagger$ show transmission electron micrograph (TEM) and Raman spectra of the MWCNTs used, respectively. The intensity ratio of D-band and G-band peaks is approximately 0.4 , suggesting a high quality of MWCNTs. The ILs and MWCNTs were used as received.

Mixtures of MWCNT-ILs were prepared following the procedure described in our previous work. ${ }^{6}$ In the case of electrolytes with $0.025 \mathrm{M}$ of $\mathrm{Co}^{\mathrm{II}}(\mathrm{bpy})_{3}\left(\mathrm{NTf}_{2}\right)_{2} / \mathrm{Co}^{\mathrm{III}}(\mathrm{bpy})_{3}\left(\mathrm{NTf}_{2}\right)_{3}$, the redox couple was added before mixing with MWCNTs. After addition of MWCNTs, each mixture was stirred on a hot plate for 30 minutes, then ultrasonicated for 30 minutes, followed by another stirring step for 15 minutes, with all steps occurring at a temperature of $65{ }^{\circ} \mathrm{C}$, in order to reach a high dispersion of MWCNTs. The samples were allowed to cool down at room temperature for at least 1 hour, followed by 5 minutes of stirring before taking measurements. Coulometric Karl Fischer titration (Titroline KF, Schott instruments) indicates water content less than 0.08 weight percent, before and after the mixing with MWCNTs (Table S1†). Widegren et al. ${ }^{\mathbf{1 9 2 0}}$ showed that water content below 0.1 weight percent have an effect of less than $4 \%$ in electrolyte conductivity and less than $7 \%$ in viscosity of imidazolium-based ILs.

\section{Electrochemical impedance spectroscopy}

Impedance spectra was performed using the same electrochemical set-up and procedure as in our previous work. ${ }^{6}$ The electrochemical setup consisted of a 2-electrode configuration with platinum electrodes. EIS was performed with $\mathrm{CH}$ instruments Model 660E potensiostat. The ac voltage amplitude was $20 \mathrm{mV}$ and the dc signal was $0 \mathrm{mV}$. The spectra ranged from 1 $\mathrm{MHz}$ to $0.02 \mathrm{~Hz}$. We measured the spectra of [EMIM] $\left.\mathrm{NTF}_{2}\right]-$ MWCNT mixtures, with and without $0.025 \mathrm{M}^{\text {of } \mathrm{Co}^{\mathrm{II}}}$ (bpy) $\left(\mathrm{NTf}_{2}\right)_{2} / \mathrm{Co}^{\mathrm{III}}(\mathrm{bpy})_{3}\left(\mathrm{NTf}_{2}\right)_{3}$, at three different temperatures: 22, 60 and $110{ }^{\circ} \mathrm{C}$. EIS results at $22^{\circ} \mathrm{C}$ are shown in Fig. 1, while the results at 60 and $110{ }^{\circ} \mathrm{C}$ are shown in Fig. S4a-d. $\dagger$ The total impedance measured was converted to conductivity using eqn (S1) and (S2). $\dagger$ The spectra in Fig. $1 \mathrm{~b}$ and $\mathrm{c}$ were fitted to the models in Fig. S3a and S3b, $\uparrow$ respectively.

\section{Thermal conductivity measurements}

A transient plane source technique with Hot Disk TPS 2500S and sensor \#7577 was used to measure the thermal conductivity of $\mathrm{Co}^{\mathrm{II} / \mathrm{III}}-[\mathrm{EMIM}]\left[\mathrm{NTf}_{2}\right]-\mathrm{MWCNT}$ and [PMIM][I]-MWCNT mixtures at room temperature. The mixtures were placed in vacuum at $70{ }^{\circ} \mathrm{C}$ for 4 hours in order to reduce moisture. We used a volume mixture of about 5-8 mL, allowed $1 \mathrm{~h}$ to reach equilibrium with surroundings, and performed 20 cycle measurements ( 5 minutes between each measurement).

\section{Stirring thermocell measurements}

The stirring thermocell consisted of two vertical graphite electrodes separated by $2.56 \mathrm{~cm}$ and immersed in $0.025 \mathrm{M}$ $\mathrm{Co}^{\mathrm{II}}(\mathrm{bpy})_{3}\left(\mathrm{NTf}_{2}\right)_{2} / \mathrm{Co}^{\mathrm{III}}(\mathrm{bpy})_{3}\left(\mathrm{NTf}_{2}\right)_{3}-[\mathrm{EMIM}]\left[\mathrm{NTf}_{2}\right]$ at different $\mathrm{wt} \%$ of MWCNTs. The average temperature of the electrolyte is set to $22^{\circ} \mathrm{C}$ by the water jacket. A magnetic bar is included in the electrolyte, and stirred with a controlled rate by the plate at the bottom. A snapshot of the experimental set-up is shown in Fig. S6a. $\dagger$ In order to create the thermoelectric effect, one of the 
electrodes is heated with thin film heaters at the top. Even though forced convection reduces thermal gradients between the electrodes, a thermal gradient at the boundary of the hot electrode and electrolyte still exists. The thermoelectric effect is maintained because redox reactions happen at the boundary layers of the electrodes.

\section{Coin-like thermocells measurements}

The thermocell consisted of platinum electrodes deposited on stainless steel substrates of $2 \mathrm{~cm}$ in diameter and separated by 2 $\mathrm{mm}$. The coin-like cell is sandwiched between two metal blocks in order to apply a temperature difference, as shown in Fig. 4a. A snapshot of the experimental set-up is shown in Fig. S6b. $\dagger$ The coin-like cells were tested under two different temperature differences, 25 and $48 \mathrm{~K}$.

\section{Results and discussion}

\section{Electrochemical impedance spectroscopy (EIS) of IL/MWCNT mixtures}

EIS of [EMIM] $\left.\mathrm{NTf}_{2}\right]$-MWCNT mixtures at room temperature (Fig. 1b) shows an increase in ohmic conductivity as MWCNTs are added, which is caused by increased interfacial polarization. ${ }^{6}$ At low weight percent of MWCNTs, there are also small changes of the dielectric spectra at low frequencies due to the formation of percolated networks. ${ }^{17}$ Above 0.3 weight percentage of MWCNTs, the spectra at low frequencies resemble a resistor, which is characteristic of a mixture above the percolation threshold. ${ }^{17,21}$ The addition of equimolar 0.025 $\mathrm{M} \mathrm{Co}{ }^{\mathrm{II}}(\mathrm{bpy})_{3}\left(\mathrm{NTf}_{2}\right)_{2}$ and $\mathrm{Co}^{\mathrm{III}}(\mathrm{bpy})_{3}\left(\mathrm{NTf}_{2}\right)_{3}$ produces charge transfer resistances in the mid-frequency range, ${ }^{22}$ but the changes in conductivity with the addition of MWCNTs (Fig. 1c) are similar to those of the IL without the redox couple. The spectra were fitted to established dielectric and redox electrochemical circuit models (Fig. S3†) to quantify resistances (Fig. 1d and e). The bulk resistance $\left(R_{\mathrm{b}}\right)$ is reduced by approximately $25 \%$ when 0.1 weight percentage of MWCNTs is added to the electrolyte. Impedance spectra collected at $60^{\circ} \mathrm{C}$ and $110{ }^{\circ} \mathrm{C}$ (Fig. S4 and S5†) show similar trends.

\section{Stirring thermocells with $\mathrm{Co}^{\mathrm{II}} / \mathrm{Co}^{\mathrm{III}}$ electrolyte}

To reduce diffusive boundary layers and isolate the performance to an ohmic limited scenario, we designed a thermocell where convection is forced by stirring the electrolyte (Fig. 2a and S6, $\uparrow$ and the Experimental section). The open circuit voltage, $V_{\text {oc}}$, is reduced as MWCNTs are added (Fig. 2b) because of electronic leakage through the partially or fully percolated networks. Forced convection cools down the surface temperature of the hot electrode, reducing the open circuit voltage. Even though thermal gradients in the bulk are diminished by forced convection, redox reactions (responsible for the open circuit voltage following eqn (1)) take place at the electrode surfaces that are still at different temperatures. As the stirring rate increases (from 400 to $600 \mathrm{rpm}$ ), forced convection reduces even more the hot electrode temperature, reducing the open circuit voltage (Fig. 2b). We note that electronic leakage is reduced significantly by the application of force convection, which appears to partially break the conductive MWCNT networks. The addition of MWCNTs increases the conductance of the cell (short circuit current, $J_{\mathrm{sc}}$, divided by $V_{\mathrm{oc}}$ ) with a trend that appears to follow a power-law (Fig. 2c), which is characteristic of mixtures with conductive particles below and near the percolation threshold. ${ }^{17,23}$ Forced convection reduces diffusive mass transfer resistances and increases the cell conductance approximately 4 -fold. The maximum power $\left(P_{\max }=V_{\mathrm{oc}} J_{\mathrm{sc}} / 4\right)$ increases as MWCNTs are added (Fig. 2d). The higher temperature at the hot electrode, and thus larger $V_{\text {oc }}$, at $400 \mathrm{rpm}$ produces more power at this rate than at higher stirring rates due to the smaller rate of heat transfer. The reduction in voltage due to percolation becomes dominant at the larger MWCNT concentrations and eventually reduces the power, so the maximum power is reached between 0.3 and 0.5 weight percentage. Without forced convection, the addition of MWCNTs in this cell design decreases the power because of percolation and slower ionic diffusion in a more viscous solution (Fig. S7†).

\section{Coin-like thermocells with $\mathrm{Co}^{\mathrm{II}} / \mathrm{Co}^{\mathrm{III}}$ electrolyte}

We also tested the coin-like thermocell performance with $\mathrm{Co}^{\mathrm{II}}(\mathrm{bpy})_{3}\left(\mathrm{NTf}_{2}\right)_{2} / \mathrm{Co}^{\mathrm{III}}(\mathrm{bpy})_{3}\left(\mathrm{NTf}_{2}\right)_{3}$ in [EMIM] $\left[\mathrm{NTf}_{2}\right]$ at different weight percentage of MWCNTs. We assembled and tested the coin-like cells as described in the Experimental section, Fig. 4a and S6b. $\uparrow$ Compared to the previous stirring design, there is not forced convection in these coin-like cells. Fig. 3a shows a significant reduction on the thermal-to-voltage conversion, $V_{\text {oc }} / \Delta T$, as we add MWCNTs. These changes due to percolated networks correlate with the impedance spectra results at low frequencies in Fig. 1. At higher temperatures, thermal energy seems to break the conductive percolated networks, ${ }^{24}$ and reduce electronic leakage at higher temperature differences, as also suggested by the data trends in Fig. S4. $\dagger$ For example, at 0.1 weight percentage, $V_{\text {oc }} / \Delta T$ increases from $1 \mathrm{mV} \mathrm{K}^{-1}$ at $17 \mathrm{~K} \Delta T$ to $1.4 \mathrm{mV} \mathrm{K}^{-1}$ at $72 \mathrm{~K} \Delta T$. In these coin-like thermocells ( $2 \mathrm{~mm}$ electrode-electrode distance), diffusion plays a significant role in power. ${ }^{2}$ The addition of MWCNTs increases the electrolyte viscosity, thus limiting ionic diffusion and power. Fig. S7a $\dagger$ shows a $20 \%$ increase in the viscosity, $\eta$, of [EMIM] $\left.\mathrm{NTf}_{2}\right]$, when 0.2 weight percentage of MWCNTs are added. This change results in lower cell conductances $\left(J_{\mathrm{sc}} / V_{\mathrm{oc}}\right)$, overshadowing the positive effects of interfacial polarization on ohmic conductivity, at 0.06 and 0.1 weight percentage (Fig. 3b). At 0.3 weight percentage, percolation is dominant, resulting in higher cell conductance than at 0 weight percentage. As the average cell temperature increases, the viscosity of [EMIM] $\left[\mathrm{NTf}_{2}\right]-\mathrm{MWCNT}$ mixtures decreases (Fig. S7b $\dagger$ ) and the cell conductance increases. Both, percolation and slower diffusion reduces the total thermocell power as MWCNTs are added (Fig. 3c).

\section{Coin-like thermocells with [PMIM][I] electrolyte}

Another approach to enhance the performance of stagnant thermocells is based on exploiting solvent-free redox ILs. We showed $^{6}$ that the addition of MWCNTs to the solvent-free redox 
a

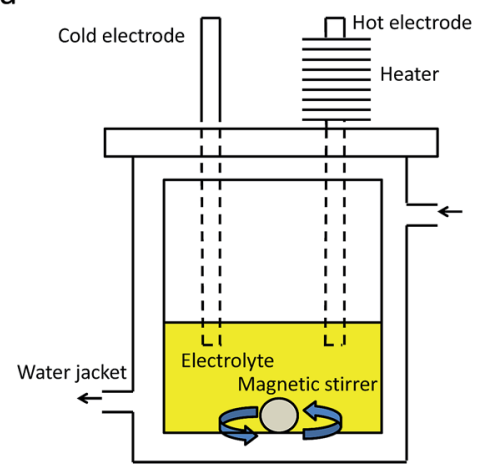

C

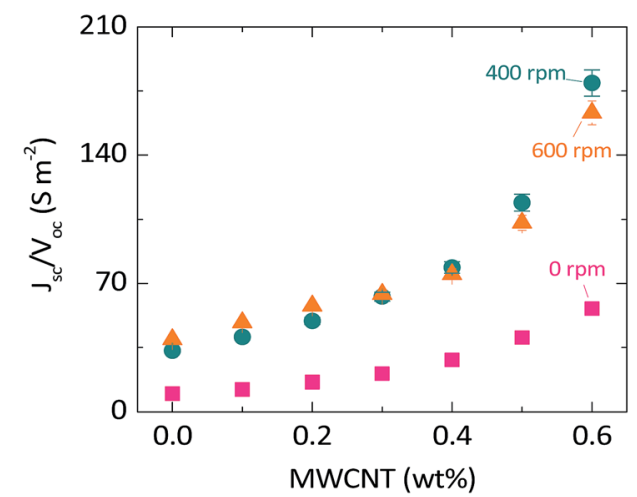

b

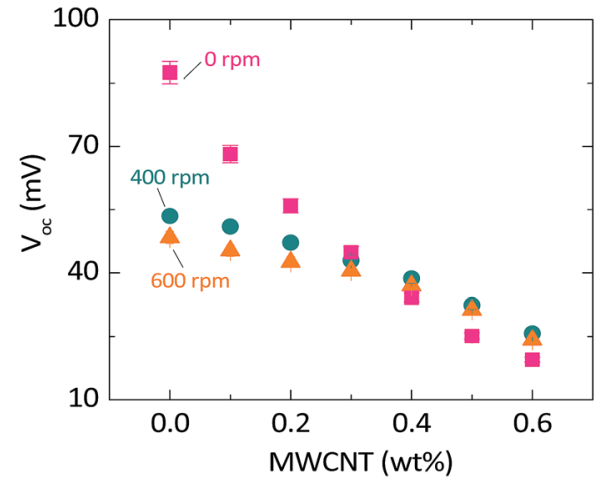

d

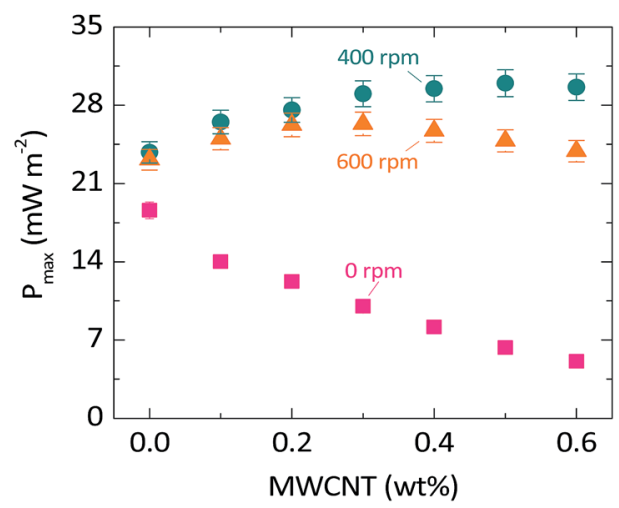

Fig. 2 Stirring thermocell performance using $0.025 \mathrm{M}$ of $\mathrm{Co}^{\prime \prime}(\mathrm{bpy})_{3}\left(\mathrm{NTf} \mathrm{f}_{2}\right)_{2} / \mathrm{Co} \mathrm{O}^{\prime \prime \prime}(\mathrm{bpy})_{3}(\mathrm{NTf})_{3}$ in $[\mathrm{EMIM}]\left[\mathrm{NTf} \mathrm{f}_{2}\right]$ and different weight percentage (wt\%) of MWCNTs. (a) Schematic representation of the experimental setup for the performance testing of stirring thermocells. (b) $V_{\text {oc }}$ is the open circuit voltage of the cell. Stirring rates tested are 0 (pink squares), 400 (green circles), 600 (orange triangles) rpm. (c) $J_{\text {sc }} / V_{o c}$ is the ratio of short circuit current density and open circuit voltage. (d) $P_{\max }$ is the maximum electrical power. The input heat power $\left(1.6 \mathrm{~W} \mathrm{~cm}^{-2}\right)$ and $\mathrm{chiller}$ temperature $\left(22^{\circ} \mathrm{C}\right)$ were kept constant in all the measurements. Measurements at $500 \mathrm{rpm}$ were also taken. These values fell between 400 and $600 \mathrm{rpm}$ values.
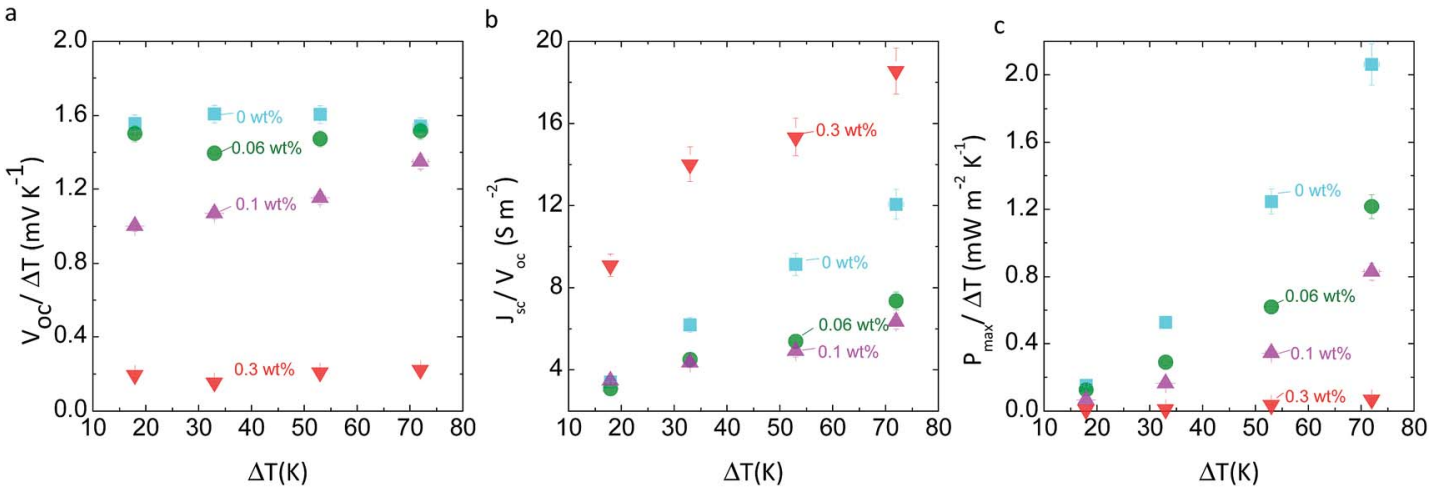

Fig. 3 Coin-like thermocell performance using $0.025 \mathrm{M}$ of $\mathrm{Co}^{\prime \prime}(\mathrm{bpy})_{3}\left(\mathrm{NTf}_{2}\right)_{2} / \mathrm{Co} \mathrm{O}^{\prime \prime \prime}(\mathrm{bpy})_{3}\left(\mathrm{NTf}_{2}\right)_{3}$ in $[\mathrm{EMIM}]\left[\mathrm{NTf} \mathrm{f}_{2}\right]$ and 0 (cyan squares), 0.06 (green circles), 0.1 (pink triangles up) and 0.3 (red triangles down) weight percentage (wt\%) of MWCNTs. (a) $V_{\text {oc }}$ is the open circuit voltage of the cell. (b) $J_{\mathrm{SC}} / V_{\mathrm{OC}}$ is the ratio of short circuit current density and open circuit voltage. (c) $P_{\mathrm{MWCNT}-\mathrm{IL}} / P_{\mathrm{IL}}$ is the ratio of maximum power using MWCNTs and without them. $\Delta T$ is the temperature difference between the electrodes. The temperature at the cold electrode was set at $23{ }^{\circ} \mathrm{C}$ in all the measurements.

IL [PMIM][I] dissociates the ion pairs, releases the anion, and increases the average diffusion coefficient of the anion. To test this effect on thermocell performance, we assembled coin-like cells with [PMIM][I] (Experimental section). The thermal-tovoltage conversion, $V_{\mathrm{oc}} / \Delta T$, is $0.12 \mathrm{mV} \mathrm{K}^{-1}$ without MWCNTs (Fig. 4b), which is more than 10 times lower than the thermal- 
a

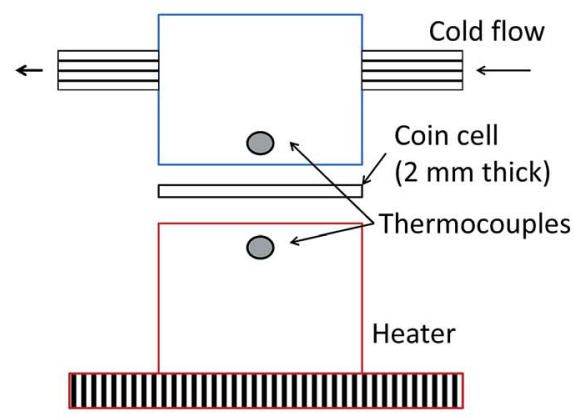

C

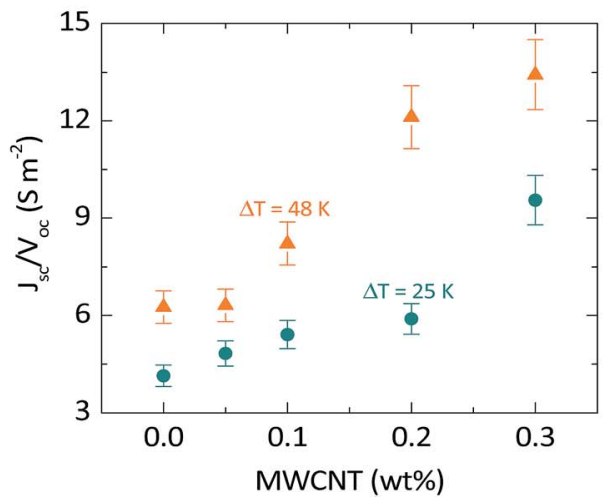

b

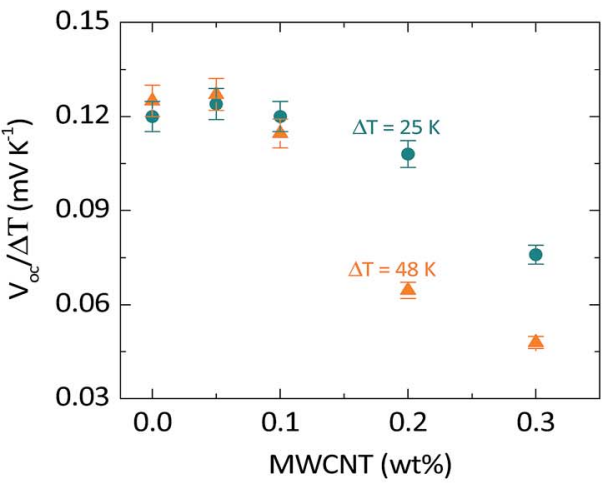

d

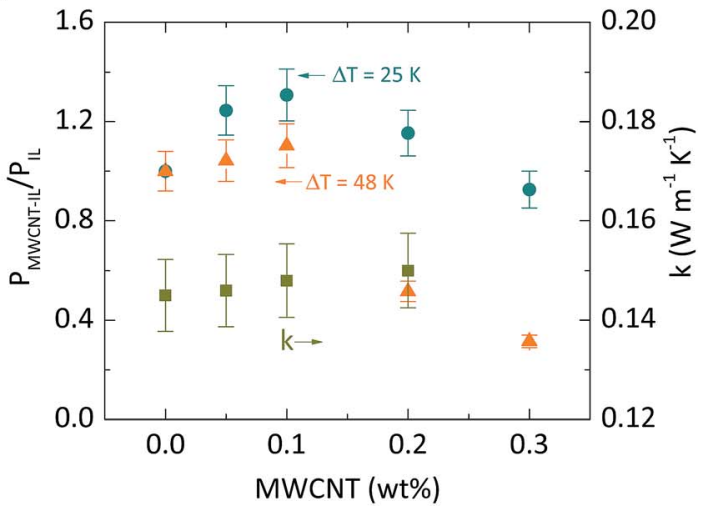

Fig. 4 Coin-like thermocell performance in [PMIM][I] at different weight percentage (wt\%) of MWCNTs. (a) Schematic representation of the experimental setup for the performance testing of coin-like thermocells. (b) $V_{\text {oc }}$ is the open circuit voltage of the cell. $\Delta T$ is the temperature difference between the electrodes, $\Delta T=25 \mathrm{~K}$ (green circles) and $\Delta T=48 \mathrm{~K}$ (red squares). The temperature at the cold electrode was set at $15^{\circ} \mathrm{C}$ in all the measurements. (c) $J_{\mathrm{SC}} / V_{\mathrm{OC}}$ is the ratio of short circuit current density and open circuit voltage. (d) $P_{\mathrm{MWCNT}-\mathrm{IL}} / P_{\mathrm{IL}}$ is the ratio of maximum power using MWCNTs and without them, while $k$ is the thermal conductivity of the mixture.

to-voltage conversion in the cobalt electrolytes $\left(1.6 \mathrm{mV} \mathrm{K}^{-1}\right)$. The thermoelectric effect remains similar up to 0.1 weight percent of MWCNTs, and then it diminishes significantly at 0.2 weight percentage due to the formation of percolated networks. The cell conductance, $J_{\mathrm{sc}} / V_{\text {oc }}$, increases with the addition of MWCNTs (Fig. 4c). At 0.05 and 0.1 weight percentage, the changes in cell conductance are mainly due to ion-pair dissociation, since percolation starts to be dominant at 0.2 weight percentage. ${ }^{6}$ Interfacial polarization also increases the ohmic conductivity, but in [PMIM][I] coin-like TECs, the power is limited by ionic diffusion. Dissociation of [PMIM] $]^{+}$and $[\mathrm{I}]^{-}$ions increases the average diffusion coefficient of $[\mathrm{I}]^{-}$ions, significantly improving the thermocell power density. This effect increases the power density by as much as 1.3 times the power without MWCNTs.

The stability of the coin-like thermocells was also tested. Table S4 $\uparrow$ shows the thermal-to-voltage conversion, $V_{\mathrm{oc}} / \Delta T$, and relative short circuit current, $J_{\mathrm{sc}} / \Delta T$, of two coin-like cells tested immediately after crimping of the cell (day 1 ) and after 30 days of resting at open circuit (day 30). The results fall within the $3 \%$ uncertainty on the open circuit voltage and $8 \%$ uncertainty on the short circuit current for initial and 30 days testing, indicating good stability of the IL-MWCNT mixtures and platinum electrodes. The changes in thermal conductivity of MWCNT- cobalt redox ILs and MWCNT-[PMIM][I] are shown in Fig. 2e and $4 \mathrm{~d}$, respectively. The mean thermal conductivity values increase less than $3 \%$ with the addition of MWCNTs, which is 8 and 10 times lower than the increase in electric power from adding MWCNTs in cobalt redox ILs and [PMIM][I], respectively. Phonon scattering ${ }^{7}$ at the interface of MWCNTs and ILs, and between MWCNTs, producing high thermal interface resistances, likely limits the increase in thermal conductivity.

\section{Conversion efficiency of thermocells}

The conversion efficiency of thermocells is evaluated using

$$
\mathrm{CE}[\%]=\frac{\text { Maximum electric power }}{\text { Input heat }}(100)
$$

and the relative efficiency with respect to the Carnot efficiency, $\mathrm{CE}_{\mathrm{r}}=\mathrm{CE}\left(T_{\mathrm{H}} / \Delta T\right)$. The maximum electrical power can be approximated as $V_{\mathrm{oc}} J_{\mathrm{sc}} / 4$, where $V_{\mathrm{oc}}$ is the open circuit voltage of the cell and $J_{\mathrm{sc}}$ is the electrical short circuit density. The input heat can be represented as $h_{\mathrm{e}} \Delta T$, where $\Delta T$ is the temperature difference between the electrodes and $h_{\mathrm{e}}$ is the effective heat transfer coefficient, which depends on the electrolyte thermal conductivity, cell thickness and, in some cases, natural or forced convection. Defining the cell conductance as $J_{\mathrm{sc}} / V_{\mathrm{oc}}$, the 
conversion efficiency of thermocells can then be approximated as

$$
\mathrm{CE}[\%]=\frac{V_{\mathrm{oc}}^{2}\left(J_{\mathrm{sc}} / 4 V_{\mathrm{oc}}\right)}{h_{\mathrm{e}} \Delta T}(100)
$$

In the stirring cell design (Fig. 2a and S6a $\dagger$ ) using $0.025 \mathrm{M}$ $\mathrm{Co}^{\mathrm{II}}(\mathrm{bpy})_{3}\left(\mathrm{NTf}_{2}\right)_{2} / \mathrm{Co}^{\mathrm{III}}(\mathrm{bpy})_{3}\left(\mathrm{NTf}_{2}\right)_{3}$ in $[\mathrm{EMIM}]\left[\mathrm{NTf}_{2}\right]$, the relative conversion efficiency without MWCNTs is approximately $0.07 \%$ (without considering the energy required to stir the electrolyte). The addition of 0.5 weight percentage of MWCNTs improves the relative conversion efficiency to $0.087 \%$. In coinlike cells using [PMIM][I] (Fig. 4a and $\mathrm{S} 6 \mathrm{~b} \dagger$ ), the relative conversion efficiency without MWCNT is approximately $5.9 \times$ $10^{-6} \%$ (at $25 \mathrm{~K}$ of $\Delta T$ ). The addition of 0.1 weight percentage of MWCNTs improves the relative conversion efficiency to $7.6 \times$ $10^{-6} \%($ at $25 \mathrm{~K}$ of $\Delta T)$.

\section{Conclusions}

We have shown that the addition of MWCNTs can improve the power of IL-based thermocells. The power increase depends on maximizing the effect of interfacial polarizations and ion pair dissociation, thus reducing mass transfer resistances; while minimizing electronic leakage that reduces the open circuit voltage. We also show that thermal conductivity of these mixtures increases to a lesser extent (8 to 10 times lower) than electric power, which can increase the efficiency of thermocells. In [PMIM][I], the MWCNTs dissociate the ion pairs, increasing the mobility of redox [I] ions. This results in a $30 \%$ increase in power in a coin-like thermocell with the addition of 0.1 weight percentage of MWCNTs. However, in [EMIM] $\left[\mathrm{NTf}_{2}\right]$ with cobalt redox couples, the addition of MWCNTs limits the diffusion of cobalt ions, resulting in lower power than with no MWCNTs in a similar coin-like thermocell. However, the addition of MWCNTs to $[\mathrm{EMIM}]\left[\mathrm{NTf}_{2}\right]$-cobalt electrolytes with forced convection, which makes the system ohmic limited, increases ohmic conductivity due to interfacial polarization. This positive effect overcomes the open circuit voltage reduction, and results in a $25 \%$ increase in power (stirring at $400 \mathrm{rpm}$ ) with the addition of 0.4 weight percentage of MWCNTs. The significance of these results is not limited to thermo-electrochemical cells, but it can be extended to improve the power of other IL-based electrochemical devices, such as redox flow batteries, fuel cells, or dyesensitized solar cells.

\section{Acknowledgements}

We are grateful for the financial support of National Science Foundation Award No. CBET 1055479. Funding from the Australian Research Council, through its Centre of Excellence Scheme, is also gratefully acknowledged. AHK is grateful for support from a Fulbright Fellowship. We are also grateful to Dr. Victor Breedveld and Dr. Hee Oh at Georgia Institute of Technology for their help with viscosity measurements.

\section{References}

1 T. I. Quickenden and Y. Mua, J. Electrochem. Soc., 1995, 142, 3985-3994.

2 P. Salazar, S. Kumar and B. Cola, J. Appl. Electrochem., 2014, 44, 325-336.

3 T. J. Abraham, D. R. MacFarlane and J. M. Pringle, Energy Environ. Sci., 2013, 6, 2639-2645.

4 O. Bubnova, Z. U. Khan, H. Wang, S. Braun, D. R. Evans, M. Fabretto, P. Hojati-Talemi, D. Dagnelund, J.-B. Arlin, Y. H. Geerts, S. Desbief, D. W. Breiby, J. W. Andreasen, R. Lazzaroni, W. M. Chen, I. Zozoulenko, M. Fahlman, P. J. Murphy, M. Berggren and X. Crispin, Nat. Mater., 2014, 13, 190-194.

5 R. Hu, B. A. Cola, N. Haram, J. N. Barisci, S. Lee, S. Stoughton, G. Wallace, C. Too, M. Thomas, A. Gestos, M. E. d. Cruz, J. P. Ferraris, A. A. Zakhidov and R. H. Baughman, Nano Lett., 2010, 10, 838-846.

6 P. F. Salazar, K. J. Chan, S. T. Stephens and B. A. Cola, J. Electrochem. Soc., 2014, 161, H481-H486.

7 S. T. Huxtable, D. G. Cahill, S. Shenogin, L. Xue, R. Ozisik, P. Barone, M. Usrey, M. S. Strano, G. Siddons, M. Shim and P. Keblinski, Nat. Mater., 2003, 2, 731-734.

8 T. Ikeshoji, Bull. Chem. Soc. Jpn., 1987, 60, 1505-1514.

9 T. I. Quickenden and C. F. Vernon, Sol. Energy, 1986, 36, 63-72. 10 N. Jiao, T. J. Abraham, D. R. MacFarlane and J. M. Pringle, J. Electrochem. Soc., 2014, 161, D3061-D3065.

11 T. J. Abraham, N. Tachikawa, D. R. MacFarlane and J. M. Pringle, Phys. Chem. Chem. Phys., 2014, 16, 2527-2532.

12 P. F. Salazar, S. Kumar and B. A. Cola, J. Electrochem. Soc., 2012, 159, B483-B488.

13 T. J. Abraham, D. R. MacFarlane and J. M. Pringle, Chem. Commun., 2011, 47, 6260-6262.

14 D. R. MacFarlane, N. Tachikawa, M. Forsyth, J. M. Pringle, P. C. Howlett, G. D. Elliott, J. H. Davis, M. Watanabe, P. Simon and C. A. Angell, Energy Environ. Sci., 2014, 7, 232-250.

15 D. Rooney, J. Jacquemin and R. Gardas, in Ionic Liquids, Springer, Berlin, Heidelberg, 2010, vol. 290, pp. 185-212.

16 C. P. Smyth, Dielectric behavior and structure: dielectric constant and loss, dipole moment and molecular structure, McGraw-Hill, 1955.

17 J. Zhang, M. Mine, D. Zhu and M. Matsuo, Carbon, 2009, 47, 1311-1320.

18 J. Wang, H. Chu and Y. Li, ACS Nano, 2008, 2, 2540-2546.

19 J. A. Widegren and J. W. Magee, J. Chem. Eng. Data, 2007, 52, 2331-2338.

20 J. A. Widegren, E. M. Saurer, K. N. Marsh and J. W. Magee, J. Chem.Thermodyn. Thermochem., 2005, 37, 569-575.

21 R. A. Huggins, Ionics, 2002, 8, 300-313.

22 V. F. Lvovich, in Impedance Spectroscopy - Applications to Electrochemical and Dielectric Phenomena, John Wiley \& Sons, 2012, pp. 97-111.

23 I. Webman, J. Jortner and M. H. Cohen, Phys. Rev. B: Solid State, 1977, 16, 2593-2596.

24 Y. Xi, Y. Bin, C. K. Chiang and M. Matsuo, Carbon, 2007, 45, 1302-1309. 